\title{
SISTEM PENDUKUNG KEPUTUSAN PENYELEKSIAN PEGAWAI NEGERI SIPIL (PNS) PROFESIONAL MENGGUNAKAN METODE FUZZY MCDM
}

\author{
Rizki Hariandi ${ }^{1)}$, Dody Putra ${ }^{2)}$, Sesti Novalina ${ }^{3)}$ \\ Program Studi Hukum Pidana Islam, Institut Agama Islam Tebo \\ Progam Studi Ekonomi Akuntansi Syariah, Institut Agama Islam Tebo \\ Progam Studi Pendidikan Islam Anak Usia Dini, Institut Agama Islam Tebo, \\ email: rizkihariandi.23@gmail.com ${ }^{1}$, dodyputra144@ gmail.com ${ }^{2)}$, novalinasesti@gmail.com $^{3)}$
}

\begin{abstract}
The quality of human resources is one of the factors to increase the productivity of an agency's performance. Therefore, an agency needs to conduct an assessment of employees work behavior to determine the success or failure of its duties. the problems that occur in the Urban, Landscaping and Cleanliness Department of Tebo Regency are the difficulties in carrying out the process of evaluating employees' work behavior effectively and efficiently. This study aims to determine professional government employees based on work behavior assessment criteria. Fuzzy MCDM in this case is used for numerical and linguistic assessments. The selection is carried out by an integral process, the inputs needed in this case are criteria and alternatives, while the output produced is the name of the most professional government employees selected.
\end{abstract}

\section{Keywords : Fuzzy MCDM, Employees, Professional, Criteria, Alternative}

\begin{abstract}
Abstrak
Kualitas sumber daya manusia merupakan salah satu faktor untuk meningkatkan produktifitas kinerja suatu instansi. Oleh karena itu, suatu instansi perlu melakukan penilaian prilaku kerja pegawai untuk mengetahui keberhasilan atau tidak berhasilnya dalam melaksanakan tugasnya. permasalahan yang terjadi di Dinas Perkotaan, Pertamanan dan Kebersihan Kabupaten Tebo yaitu sulitnya melakukan proses penilaian prilaku kerja pegawai secara efektif dan efesien. Penelitian ini bertujuan untuk menentukan Pegawai Negeri Sipil profesional berdasarkan dari kriteria penilaian prilaku kerja. Fuzzy MCDM dalam hal ini digunakan untuk penilaian secara numeris dan linguistic. Untuk penyeleksiannya dilakukan dengan proses integral, Input yang diperlukan dalam kasus ini yaitu kriteria dan alternatif, sementara output yang dihasilkan adalah nama pengawai negeri sipil yang terpilih paling profesional.
\end{abstract}

Kata Kunci : Fuzzy MCDM, Pegawai, Profesional, Kriteria, Alternatif

\section{PENDAHULUAN}

Dinas Perkotaan, Pertamanan Dan Kebersihan Kabupaten Tebo sebagai birokrasi pemerintah merupakan salah satu unit kerja dilingkungan Pemerintah Kabupaten Tebo. Tercapainya organisasi sangat ditentukan dengan prilaku kerja pegawainya dalam menjalankan tugasnya secara profesional sehingga memiliki kualitas pelayanan sesuai yang diharapkan.

Untuk meningkatkan kualitas Pegawai Negeri Sipil di lingkungan pemerintahan kabupaten tebo maka dilakukan penyeleksian terhadap Pegawai Negeri Sipil Profesional. Sebelum ini untuk menentukan kelayakan seorang Pegawai Negeri Sipil profesional dilakukan secara 
manual. Diharapkan dengan adanya aplikasi penyeleksian Pegawai Negeri Sipil Profesional ini dapat membantu proses penilaian prilaku kerja menjadi lebih efektif dan efesien.

Sistem Pendukung Keputusan adalah sistem yang berbasis komputer yang dapat membantu pengambilan keputusan untuk memecahkan masalah tertentu dengan memanfaatkan data dan model tertentu. Pada dasarnya SPK merupakan pengembangan lebih lanjut dari Sistem Informasi Manajemen terkomputerisasi yang dirancang sedemikian rupa sehingga bersifat interaktif dengan pemakainya. Interaktif dengan tujuan untuk memudahkan integrasi antara berbagai komponen dalam proses pengambilan keputusan seperti prosedur, kebijakan, analisis, pengalaman dan wawasan manajer untuk mengambil keputusan yang lebih baik (Aldo, 2019).

Sistem Pendukung Keputusan (SPK) adalah bagian dari sistem informasi berbasis komputer termasuk sistem berbasis pengetahuan atau manajemen pengetahuan yang dipakai untuk mendukung pengambilan keputusan dalam suatu organisasi atau perusahaan (Antoni Aruan 2014).

Jenis keputusan dibagi menjadi tiga :

1. Keputusan Terstruktur (Structured Decision)

2. Keputusan Semiterstruktur (Semistructured Decision)

3. Keputusan Tak Terstruktur (Unstructured Decision) (Abdul kadir dan Terra C 2012).

Komponen sistem pendukung keputusan meliputi 8 bagian yaitu :

1. Hardware Resourches

2. Software Resources

3. Sumber Data
4. Sumber Model

5. Sumber Daya manusia

6. Model Sistem Pendukung Keputusan

7. Electronic Spreadsheet

8. Sistem Pendukung Keputusan Kelompok (Menurut sudiantoro dalam Amelia Yusnita dan Rosiana Handini 2012)

Adapun tujuan dari penelitian ini adalah membangun suatu aplikasi yang dapat membantu dalam menentukan Pegawai Negeri Sipil Profesional menggunakan metode Fuzzy MCDM.

Kajian Literatur

Fuzzy Multiple Criteria Decision Making (FMCDM) adalah metode untuk membantu pengambilan keputusan terhadap beberapa alternatif keputusan yang harus diambil dengan mempertimbangkan beberapa kriteria (Sri Winarso Martyas Edi, et al 2014). Teori dasar Multi Criteria Decision Makingadalah hasil alternatif yang telah dikenal dan ditentukan sebelumnya untuk pegambilan keputusan berdasarkan data kriteria (Hamdania dan Retantyo Wardoyo 2015).

\section{METODE PENELITIAN}

\section{Teknik Pengumpulan Data}

Metode pengumpulan data yang digunakan dalam penelitian ini adalah dengan melakukan metode interview kepada narasumber yaitu Kepala Dinas Perkotaan Pertamanan dan Kebersihan Kabupaten Tebo. Dalam melakukan pengumpulan data ini dikumpulkan informasi data pegawai negeri sipil, kriteria penilaian prilaku kerja pegawai yang akan digunakan dan pengisian daftar pertanyaan 
untuk merangkum nilai data kecocokan dan data kepentingan dalam setiap penilaian.

\section{Representasi Masalah}

a. Tujuan keputusan ini untuk melakukan penyeleksian pegawai negeri sipil profesional berdasarkan kriteria-kriteria yang telah ditentukan. Terdapat 19 alternatif dalam kasus ini yaitu Ahmad Ikhsan, SE $\left(\mathrm{A}_{1}\right)$, Suryani, SE $\left(\mathrm{A}_{2}\right)$, Matnu Bahdis $\left(\mathrm{A}_{3}\right)$, Timur Suryantara, ST (A4), Pebri Ardiyansyah, ST (A5), Nurdiansyah ( $\left.\mathrm{A}_{6}\right)$, Eva Nauli $\left(\mathrm{A}_{7}\right)$, Achmad Muzzamil (A8), Bambang Iswandi (A9), Pauzi ( $\left.\mathrm{A}_{10}\right)$, Nuhari $\left(\mathrm{A}_{11}\right)$, Ahmad Johan $\left(\mathrm{A}_{12}\right)$, Heli Aprozi $\left(\mathrm{A}_{13}\right)$, A.Rifa'i $\left(\mathrm{A}_{14}\right)$, Usnah Novriza $\left(\mathrm{A}_{15}\right)$, Desi Yusnita ( $\left.A_{16}\right)$, M.Komi ( $\left.A_{17}\right)$, Edi Suhendra $\left(\mathrm{A}_{18}\right)$, Khoirul Ihsan $\left(\mathrm{A}_{19}\right)$.

b. Adapun kriteria yang digunakan sebanyak 5 kriteria yaitu Orientasi Pelayanan $\left(\mathrm{C}_{1}\right), \quad$ Integritas $\left(\mathrm{C}_{2}\right)$, Komitmen $\left(\mathrm{C}_{3}\right), \quad$ Disiplin $\left(\mathrm{C}_{4}\right)$, Kerjasama $\left(\mathrm{C}_{5}\right)$, yang mana kriteria di atas sudah ditentukan dari PP No. 46 Tahun 2011 tentang penilaian prilaku kerja Pegawai Negeri Sipil.

\section{HASIL DAN PEMBAHASAN}

\section{Evaluasi Himpunan Fuzzy dari alternatif-alternatif keputusan}

a. Variabel-variabel linguistic yang mempresentasikan bobot kepentingan untuk setiap kriteria, adalah : $\mathrm{T}($ Kepentingan $\mathrm{W}=\{\mathrm{SR}, \mathrm{R}, \mathrm{C}, \mathrm{T}, \mathrm{ST}\}$ dengan $\mathrm{SR}=$ Sangat Rendah, $\mathrm{R}=$ Rendah, $\mathrm{C}=$ Cukup,$\quad \mathrm{T}=$ Tinggi,$\quad \mathrm{ST}=$ Sangat Tinggi, yang masing-masing dijabarkan dengan bilangan fuzzy segitiga sebagai berikut :

1. $\mathrm{SR}=(0,0,0.3)$

2. $\mathrm{R}=(0,0.3,0.6)$

3. $\mathrm{C}=(0.3,0.6,0.8)$

4. $\mathrm{T}=(0.6,0.8,1)$

5. $\mathrm{ST}=(0.8,1,1)$

JURSIMA

Jurnal Sistem Informasi dan Manajemen b. Derajat kecocokan alternatif derajat kecocokan alternatif - alternatif dengan kriteria keputusan adalah : $\mathrm{T}$ (kecocokan) $\mathrm{S}=\{\mathrm{BR}, \mathrm{K}, \mathrm{C}, \mathrm{B}, \mathrm{SB}\}$ dengan $\mathrm{BR}=$ Buruk, $\mathrm{K}=$ Kurang, $\mathrm{C}=$ Cukup, B = Baik, SB = Sangat Baik, yang mana masing-masing dipresentasikan dengan bilangan bilangan fuzzy segitiga sebagai berikut:

1. $\mathrm{BR}=(0,0,0.3)$

2. $\mathrm{K}=(0,0.3,0.6)$

3. $\mathrm{C}=(0.3,0.6,0.8)$

4. $\mathrm{B}=(0.6,0.8,1)$

5. $\mathrm{SB}=(0.8,1,1)$

c. Rating untuk setiap kriteria seperti terlihat pada Tabel 1. Sedangkan derajat kecocokan kriteria keputusan dan alternatif pada tabel berikut :

Tabel 1. Kriteria

\begin{tabular}{|c|l|}
\hline Kriteria & \multicolumn{1}{|c|}{ Keterangan } \\
\hline $\mathrm{C}_{1}$ & Orientasi Pelayanan \\
\hline $\mathrm{C}_{2}$ & Integritas \\
\hline $\mathrm{C}_{3}$ & Komitmen \\
\hline $\mathrm{C}_{4}$ & Disiplin \\
\hline $\mathrm{C}_{5}$ & Kerjasama \\
\hline
\end{tabular}

Berikut tabel kecocokan setiap alternatif pada setiap kriteria :

Tabel 2. Rating Kecocokan

\begin{tabular}{|c|c|c|c|c|c|}
\hline \multirow{2}{*}{ Alternatif } & \multicolumn{5}{|c|}{ Rating Kecocokan } \\
\cline { 2 - 6 } & $\mathrm{C}_{1}$ & $\mathrm{C}_{2}$ & $\mathrm{C}_{3}$ & $\mathrm{C}_{4}$ & $\mathrm{C}_{5}$ \\
\hline $\mathrm{A}_{1}$ & $\mathrm{SB}$ & $\mathrm{B}$ & $\mathrm{B}$ & $\mathrm{C}$ & $\mathrm{B}$ \\
\hline $\mathrm{A}_{2}$ & $\mathrm{~B}$ & $\mathrm{~B}$ & $\mathrm{~B}$ & $\mathrm{C}$ & $\mathrm{B}$ \\
\hline $\mathrm{A}_{3}$ & $\mathrm{~B}$ & $\mathrm{SB}$ & $\mathrm{B}$ & $\mathrm{C}$ & $\mathrm{B}$ \\
\hline $\mathrm{A}_{4}$ & $\mathrm{~B}$ & $\mathrm{~B}$ & $\mathrm{C}$ & $\mathrm{C}$ & $\mathrm{B}$ \\
\hline $\mathrm{A}_{5}$ & $\mathrm{~B}$ & $\mathrm{~B}$ & $\mathrm{~B}$ & $\mathrm{C}$ & $\mathrm{B}$ \\
\hline $\mathrm{A}_{6}$ & $\mathrm{~B}$ & $\mathrm{~B}$ & $\mathrm{C}$ & $\mathrm{B}$ & $\mathrm{B}$ \\
\hline $\mathrm{A}_{7}$ & $\mathrm{~B}$ & $\mathrm{SB}$ & $\mathrm{C}$ & $\mathrm{B}$ & $\mathrm{B}$ \\
\hline $\mathrm{A}_{8}$ & $\mathrm{SB}$ & $\mathrm{B}$ & $\mathrm{B}$ & $\mathrm{B}$ & $\mathrm{B}$ \\
\hline $\mathrm{A}_{9}$ & $\mathrm{SB}$ & $\mathrm{B}$ & $\mathrm{C}$ & $\mathrm{C}$ & $\mathrm{B}$ \\
\hline $\mathrm{A}_{10}$ & $\mathrm{~B}$ & $\mathrm{~B}$ & $\mathrm{~B}$ & $\mathrm{C}$ & $\mathrm{B}$ \\
\hline
\end{tabular}

https://ejournal.stmikgici.ac.id/ sSTMIK GICI 


\begin{tabular}{|c|c|c|c|c|c|}
\hline $\mathrm{A}_{11}$ & $\mathrm{~B}$ & $\mathrm{~B}$ & $\mathrm{~B}$ & $\mathrm{~B}$ & $\mathrm{~B}$ \\
\hline $\mathrm{A}_{12}$ & $\mathrm{SB}$ & $\mathrm{B}$ & $\mathrm{B}$ & $\mathrm{C}$ & $\mathrm{B}$ \\
\hline $\mathrm{A}_{13}$ & $\mathrm{~B}$ & $\mathrm{~B}$ & $\mathrm{~B}$ & $\mathrm{C}$ & $\mathrm{B}$ \\
\hline $\mathrm{A}_{14}$ & $\mathrm{~B}$ & $\mathrm{SB}$ & $\mathrm{B}$ & $\mathrm{C}$ & $\mathrm{B}$ \\
\hline $\mathrm{A}_{15}$ & $\mathrm{~B}$ & $\mathrm{~B}$ & $\mathrm{C}$ & $\mathrm{C}$ & $\mathrm{B}$ \\
\hline $\mathrm{A}_{16}$ & $\mathrm{SB}$ & $\mathrm{B}$ & $\mathrm{B}$ & $\mathrm{C}$ & $\mathrm{B}$ \\
\hline $\mathrm{A}_{17}$ & $\mathrm{~B}$ & $\mathrm{~B}$ & $\mathrm{~B}$ & $\mathrm{C}$ & $\mathrm{B}$ \\
\hline $\mathrm{A}_{18}$ & $\mathrm{SB}$ & $\mathrm{B}$ & $\mathrm{C}$ & $\mathrm{B}$ & $\mathrm{B}$ \\
\hline $\mathrm{A}_{19}$ & $\mathrm{~B}$ & $\mathrm{~B}$ & $\mathrm{C}$ & $\mathrm{C}$ & $\mathrm{B}$ \\
\hline
\end{tabular}

Dengan mensubstitusikan bilangan fuzzy segitiga ke setiap variabel linguistic kedalam persamaan, diperoleh nilai kecocokan fuzzy seperti detail perhitungan dibawah ini:

$Y_{1}$

$=1 / 5((\mathrm{ST} * \mathrm{SB})+(\mathrm{T} * \mathrm{~B})+(\mathrm{T} * \mathrm{~B})+(\mathrm{T} *$

$\mathrm{C})+(\mathrm{C} * \mathrm{~B}))$

$=1 / 5 *((0.8 * 0.8)+(0.6 * 0.6)+(0.6 * 0.6)+(0.6$

$* 0.3)+(0.3 * 0.6))$

$=0,344$

$Q_{1}$

$=1 / 5((\mathrm{ST} * \mathrm{SB})+(\mathrm{T} * \mathrm{~B})+(\mathrm{T} * \mathrm{~B})+(\mathrm{T} *$

$\mathrm{C})+(\mathrm{C} * \mathrm{~B}))$

$=1 / 5 *((1 * 1)+(0.8 * 0.8)+(0.8 * 0.8)+(0.8 * 0.6$

)$+(0.6 * 0.8))$

$=0,648$

$\mathrm{Z}_{1}$

$=1 / 5((\mathrm{ST} * \mathrm{SB})+(\mathrm{T} * \mathrm{~B})+(\mathrm{T} * \mathrm{~B})+(\mathrm{T} *$

$\mathrm{C})+(\mathrm{C} * \mathrm{~B}))$

$=1 / 5 *((1 * 1)+(1 * 1)+(1 * 1)+(1 * 0.8)+(0.8 * 1)$

)

$=0,92$

Berikut tabel indeks kecocokan fuzzy dari semua perhitungan yang telah dilakukan.

Tabel 3. Index Kecocokan Fuzzy

\begin{tabular}{|c|c|c|c|}
\hline \multirow{2}{*}{ Alternatif } & \multicolumn{3}{|c|}{ Index Kecocokan $\boldsymbol{F u z z y}$} \\
\cline { 2 - 4 } & $\mathbf{Y}$ & $\mathbf{Q}$ & $\mathbf{Z}$ \\
\hline A1 & 0,344 & 0,648 & 0,92 \\
\hline
\end{tabular}

JURSIMA

Jurnal Sistem Informasi dan Manajemen

\begin{tabular}{|c|c|c|c|}
\hline A2 & 0,312 & 0,608 & 0,92 \\
\hline A3 & 0,336 & 0,64 & 0,92 \\
\hline A4 & 0,276 & 0,576 & 0,88 \\
\hline A5 & 0,312 & 0,608 & 0,92 \\
\hline A6 & 0,312 & 0,608 & 0,92 \\
\hline A7 & 0,336 & 0,64 & 0,92 \\
\hline A8 & 0,38 & 0,68 & 0,96 \\
\hline A9 & 0,308 & 0,616 & 0,88 \\
\hline A10 & 0,312 & 0,608 & 0,92 \\
\hline A11 & 0,348 & 0,64 & 0,96 \\
\hline A12 & 0,344 & 0,648 & 0,92 \\
\hline A13 & 0,312 & 0,608 & 0,92 \\
\hline A14 & 0,336 & 0,64 & 0,92 \\
\hline A15 & 0,276 & 0,576 & 0,88 \\
\hline A16 & 0,344 & 0,648 & 0,92 \\
\hline A17 & 0,312 & 0,608 & 0,92 \\
\hline A18 & 0,344 & 0,648 & 0,92 \\
\hline A19 & 0,276 & 0,576 & 0,88 \\
\hline
\end{tabular}

Menyeleksi alternatif yang optimal

a. Dengan mensubstistusikan indeks fuzzy kepersamaan 6 , dan mengambil derajat keoptimisan $(\alpha)=0$ (tidak optimis), $\alpha=0.5$ dan $\alpha=1$ (sangat optimis);

$\mathrm{A}_{1}=\mathrm{I}^{\frac{0}{1}} \frac{0}{1}=\left(\frac{1}{2}\right) *\left((0) *\left(\frac{1}{2}\right) *((0) *(0.92)\right.$

$+(0.648)+(1-0) *(0.344))=0.496$

$\mathrm{A}_{2}=\mathrm{I}^{\frac{0}{1} \frac{0}{1}}=\left(\frac{1}{2}\right) *\left((0) *\left(\frac{1}{2}\right) *((0) *(0.92)\right.$

$+(0.608)+(1-0) *(0.312))=0.46$

$\mathrm{A}_{3} \mathrm{I}^{\frac{0}{1} \frac{0}{1}}=\left(\frac{1}{2}\right) *\left((0) *\left(\frac{1}{2}\right) *((0) *(0.92)+\right.$ $(0.64)+(1-0) *(0.336))=0.488$

$\mathrm{A}_{4} \mathrm{I} \frac{0}{1} \frac{0}{1}=\left(\frac{1}{2}\right) *\left((0) *\left(\frac{1}{2}\right) *((0) *(0.88)+\right.$ $(0.576)+(1-0) *(0.276))=0.426$

$\mathrm{A}_{5} \mathrm{I}^{\frac{0}{1} \frac{0}{1}}=\left(\frac{1}{2}\right) *\left((0) *\left(\frac{1}{2}\right) *((0) *(0.92)+\right.$ $(0.608)+(1-0) *(0.312))=0.46$

$\mathrm{A}_{6} \mathrm{I}^{\frac{0}{1}} \frac{0}{1}=\left(\frac{1}{2}\right) *\left((0) *\left(\frac{1}{2}\right) *((0) *(0.92)+\right.$ $(0.608)+(1-0) *(0.312))=0.46$ sSTMIK GICI 


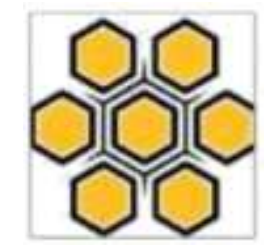

$\mathrm{A}_{7} \mathrm{I}^{\frac{0}{1}} \frac{0}{1}=\left(\frac{1}{2}\right) *\left((0) *\left(\frac{1}{2}\right) *((0) *(0.92)+\right.$ $(0.64)+(1-0) *(0.336))=0.488$

$\mathrm{A}_{8} \mathrm{I}^{\frac{0}{1} \frac{0}{1}}=\left(\frac{1}{2}\right) *\left((0) *\left(\frac{1}{2}\right) *((0) *(0.96)+\right.$ $(0.68)+(1-0) *(0.38))=0.53$

$\mathrm{A}_{9} \mathrm{I} \frac{0}{1} \frac{0}{1}=\left(\frac{1}{2}\right) *\left((0) *\left(\frac{1}{2}\right) *((0) *(0.88)+\right.$ $(0.616)+(1-0) *(0.308))=0.462$

$\mathrm{A}_{10} \mathrm{I} \frac{0}{1} \frac{0}{1}=\left(\frac{1}{2}\right) *\left((0) *\left(\frac{1}{2}\right) *((0) *(0.92)+\right.$ $(0.608)+(1-0) *(0.312))=0.46$

$\mathrm{A}_{11} \mathrm{I} \frac{0}{1} \frac{0}{1}=\left(\frac{1}{2}\right) *\left((0) *\left(\frac{1}{2}\right) *((0) *(0.96)+\right.$ $(0.64)+(1-0) *(0.348))=0.494$

$\mathrm{A}_{12} \mathrm{I} \frac{0}{1} \frac{0}{1}=\left(\frac{1}{2}\right) *\left((0) *\left(\frac{1}{2}\right) *((0) *(0.92)+\right.$ $(0.648)+(1-0) *(0.344))=0.496$

$\mathrm{A}_{13} \mathrm{I} \frac{0}{1} \frac{0}{1}=\left(\frac{1}{2}\right) *\left((0) *\left(\frac{1}{2}\right) *((0) *(0.92)+\right.$ $(0.608)+(1-0) *(0.312))=0.46$

$\mathrm{A}_{14} \mathrm{I}^{\frac{0}{1}} \frac{0}{1}=\left(\frac{1}{2}\right) *\left((0) *\left(\frac{1}{2}\right) *((0) *(0.88)+\right.$ $(0.64)+(1-0) *(0.336))=0.488$

$\mathrm{A}_{15} \mathrm{I}^{\frac{0}{1}} \frac{\mathrm{0}}{1}=\left(\frac{1}{2}\right) *\left((0) *\left(\frac{1}{2}\right) *((0) *(0.88)+\right.$ $(0.576)+(1-0) *(0.276))=0.426$

$\mathrm{A}_{16} \mathrm{I} \frac{0}{1} \frac{0}{1}=\left(\frac{1}{2}\right) *\left((0) *\left(\frac{1}{2}\right) *((0) *(0.92)+\right.$ $(0.648)+(1-0) *(0.344))=0.496$

$\mathrm{A}_{17} \mathrm{I} \frac{0}{1} \frac{0}{1}=\left(\frac{1}{2}\right) *\left((0) *\left(\frac{1}{2}\right) *((0) *(0.92)+\right.$ $(0.608)+(1-0) *(0.312))=0.46$ $\mathrm{A}_{18} \mathrm{I} \frac{0}{1} \frac{0}{1}=\left(\frac{1}{2}\right) *\left((0) *\left(\frac{1}{2}\right) *((0) *(0.92)+\right.$ $(0.648)+(1-0) *(0.344))=0.496$

$\mathrm{A}_{19} \mathrm{I} \frac{0}{1} \frac{0}{1}=\left(\frac{1}{2}\right) *\left((0) *\left(\frac{1}{2}\right) *((0) *(0.88)+\right.$ $(0.576)+(1-0) *(0.276))=0.426$

Berikut tabel total hasil nilai integral setiap alternatif :

Tabel 4. Nilai Total Integral

\begin{tabular}{|c|c|c|c|}
\hline Alternatif & \multicolumn{3}{|c|}{ Nilai Total Integral } \\
\hline & $(\alpha)=0$ & $(\alpha)=0.5$ & $(\alpha)=1$ \\
\hline A1 & 0,496 & 0,64 & 0,784 \\
\hline A2 & 0,46 & 0,612 & 0,764 \\
\hline A3 & 0,488 & 0,634 & 0,78 \\
\hline A4 & 0,426 & 0,577 & 0,728 \\
\hline
\end{tabular}




\section{DAFTAR PUSTAKA}

[1] A. Antoni, "Sistem Pendukung Keputusan Pemilihan Asuransi Jiwa Menggunakan Metode Fuzzy Multi Criteria Decision Making," Pelita Informatika Budi Darma, vol. VII, hlm. 12-15, 2014.

[2] Aldo, D. (2019). Pemilihan Bibit Lele Unggul dengan Menggunakan Metode Weighted Product. Jurnal Teknologi dan Open Source, 2(1), 15-23.

[3] A. Yusnita dan R. Handini, "Sistem pendukung keputusan Menentukan lokasi rumah makan yang strategis menggunakan metode Naïve Bayes," Seminar Nasional Teknologi Informasi \& Komunikasi Terapan 2012 (Semantik 2012), 2012, hlm. 290-294.

[4] S. Winarso, K. Dwi, dan S. Yulianto, "Optimization of Group Decision Support System in Updated Pranata Mangsa System Using Fuzzy Multi Criteria Decision Making (FMCDM) Method," IJCSI International Journal of Computer Science Issues, vol. 11, no. 1, hlm. 35-44, 2014.

[5] Hamdani dan R. Wardoyo, "A Review on fuzzy multi-criteria decision making land clearing for oil palm plantation," International Journal of Advances in Intelligent Informatics, vol. 1, hlm. 75-83, 2015. 